\title{
Synergistic effect of mycophenolate mofetil and angiotensin-converting enzyme inhibitor in patients with chronic allograft nephropathy
}

\author{
G.T. Moscoso-Solorzano ${ }^{1}$, G. Mastroianni-Kirsztajn ${ }^{1}$, K.S. Ozaki ${ }^{1}$, M.F. Franco², \\ A. Pacheco-Silva ${ }^{1}$ and N.O.S. Câmara ${ }^{1,3}$ \\ ${ }^{1}$ Laboratório de Imunologia Clínica e Experimental, Disciplina de Nefrologia, Hospital do Rim e \\ Hipertensão, ${ }^{2}$ Departamento de Patologia, Universidade Federal de São Paulo, São Paulo, SP, Brasil \\ ${ }^{3}$ Laboratório de Imunobiologia de Transplantes, Departamento de Imunologia, Instituto de Ciências \\ Biomédicas IV, Universidade de São Paulo, São Paulo, SP, Brasil
}

Correspondence to: N.O.S. Câmara, Disciplina de Nefrologia, UNIFESP, Rua Botucatu, 740, 04023-900 São Paulo, SP, Brasil

Fax: +55-11-5573-9652. E-mail: niels@nefro.epm.br

Experimental data and few clinical non-randomized studies have shown that inhibition of the renin-angiotensin system by angiotensin-converting enzyme (ACE) associated or not with the use of mycophenolate mofetil (MMF) could delay or even halt the progression of chronic allograft nephropathy (CAN). In this retrospective historical study, we investigated whether ACE inhibition (ACEI) associated or not with the use of MMF has the same effect in humans as in experimental studies and what factors are associated with a clinical response. A total of 160 transplant patients with biopsy-proven CAN were enrolled. Eightyone of them were on ACE therapy (G1) and 80 on ACEl-free therapy (G2). Patients were further stratified for the use of MMF. G1 patients showed a marked decrease in proteinuria and stabilized serum creatinine with time. Five-year graft survival after CAN diagnosis was more frequent in G1 (86.9 vs 67.7\%; P < 0.05). In patients on ACEl-free therapy, the use of MMF was associated with better graft survival. The use of ACEI therapy protected $79 \%$ of the patients against graft loss $(\mathrm{OR}=0.079,95 \% \mathrm{Cl}=0.015-$ $0.426 ; P=0.003$ ). ACEI and MMF or the use of MMF alone after CAN diagnosis conferred protection against graft loss. This finding is well correlated with experimental studies in which ACEI and MMF interrupt the progression of chronic allograft dysfunction and injury. The use of ACEI alone or in combination with MMF significantly reduced proteinuria and stabilized serum creatinine, consequently improving renal allograft survival.

Key words: Renin-angiotensin system; Mycophenolate mofetil; Renal allograft survival; Kidney transplantation

Research supported by CNPq and by Fundação Osvaldo Ramos. Publication supported by FAPESP.

Received January 17, 2008. Accepted March 2, 2009

\section{Introduction}

Chronic allograft nephropathy (CAN) is present in 40$60 \%$ of allograft biopsies 24 months after transplantation and is the most common cause of late renal graft failure $(1,2)$. CAN is characterized by progressive deterioration of renal function produced by sclerotic changes affecting blood vessels, glomeruli, interstitium, and tubules and is graded according to the degree of damage to the last two parameters (3). Even though the functional and morphologic findings of CAN have been well characterized, the progressive mechanisms leading to deterioration of graft function are poorly understood (4). Apart from the classical immune events, many other risk factors are implicated in the loss of nephron mass that might involve activation of the renin-angiotensin system (RAS) $(5,6)$. 
In this respect, the pharmacological inhibition of angiotensin II synthesis and/or the blockade of its biological activity remarkably ameliorate the renal interstitial abnormalities, reducing the accumulation of protein casts and ultimately slowing the progression of renal dysfunction in many renal disease models (7-13). Furthermore, nonrandomized clinical trials have identified the blockade of RAS as a cardinal means of arresting the progression of renal disease, delaying the progression of glomerulosclerosis and interstitial fibrosis in proteinuric diseases as well as CAN (14-21). Some non-randomized clinical studies on renal transplantation have shown that the blockade of RAS was safe and beneficial by reducing proteinuria, besides increasing renal allograft survival (19-21).

Mycophenolate mofetil (MMF) has been used in solid organ transplants with good results on the reduction of acute rejection episodes and promoting good graft survival (22-27). The effect of combined therapy with an angiotensin-converting enzyme inhibitor (ACEI) and MMF has only been analyzed in experimental studies, which showed a synergistic effect in reducing renal damage (28-30). So far, no studies have confirmed or denied these findings in humans. To answer the question of whether ACEI in combination with MMF has the same effect in humans, we designed this study with patients with biopsy-proven CAN under ACEI therapy or not, in combination or not with MMF. Factors associated with a better clinical response and with improved graft outcomes were investigated. We anticipated that the use of ACEI would delay the progression of chronic allograft nephropathy and the use of MMF would enhance the renoprotective action of ACEI, consequently decreasing renal allograft loss in patients with CAN.

\section{Subjects and Methods}

\section{Subjects}

For this retrospective study, a total of 250 consecutive renal transplant patients with a previous biopsy-proven CAN were enrolled between 2000 and 2002. The study was approved by the local Ethics Committee of São Paulo University. Patients were excluded if: 1) they were the recipients of a previous organ transplant $(\mathrm{N}=9) ; 2)$ they were the recipients of a multiple organ transplant $(\mathrm{N}=4) ; 3$ ) their biopsy samples could not be recovered for re-analysis $(N=12) ; 4)$ the results of biopsy re-analysis did not meet the minimal Banff criteria for CAN (N=4); 5) had recurrence or de novo occurrence of glomerulopathies post-transplantation ( $\mathrm{N}=51$ ), or 6 ) had neoplasias or polyomavirus infections $(\mathrm{N}=9)$. Thus, 161 transplant patients with biopsy-proven CAN were evaluated.

\section{Study design}

In this retrospective study, after a biopsy-proven diagnosis of CAN, the enrolled patients were divided into two groups defined by the use or not of ACEI therapy for at least 16 weeks before the diagnosis of CAN. The characteristics of the ACEl therapy group (N=81, G1) and the non-ACEl therapy group ( $N=80, G 2)$ were then compared. The main clinical indication of ACEI therapy was hypertension and captopril was the drug used for all G1 patients. The groups were matched for gender, type of donor (deceased versus living donor), pre-transplant disease and time of CAN diagnosis and CAN Banff grade.

\section{Stratification according to MMF use}

The two groups (G1 and G2) were also subdivided based on MMF use and the ACEl group (G1) was subdivided into three subgroups: patients who received $A C E I$ alone $(N=12)$, patients who received $A C E I$ and $M M F$ before a biopsy-proven diagnosis of CAN ( $N=14)$, and patients who received ACEI and MMF after a biopsyproven diagnosis of CAN $(N=55)$. Similarly, patients who did not use ACEI (G2) were also subdivided into three subgroups: patients who did not receive ACEI or MMF ( $N=$ 19), patients who did not receive ACEI but received MMF before a biopsy-proven diagnosis of CAN ( $N=18)$, and patients who did not receive $A C E I$, but received MMF after a biopsy-proven diagnosis of CAN $(\mathrm{N}=43)$.

\section{Operational definitions}

Delayed graft function was defined as the requirement of dialysis during the first week after transplantation in the absence of rejection and/or technical problems. Acute rejection confirmed by biopsy was defined according to Banff 97 criteria. Any rejection before the 3rd month of transplantation was classified as early acute rejection, and as late rejection after this period. Systemic arterial hypertension was defined as a repeatedly elevated blood pressure exceeding $140 \times 90 \mathrm{mmHg}$ or when patients were using at least one antihypertensive drug. New-onset diabetes after transplantation was defined when fasting plasma glucose was $\geq 126 \mathrm{mg} / \mathrm{dL}$ ( $\geq 7 \mathrm{mmol} / \mathrm{L}$ ), when a random blood sugar level $\geq 200 \mathrm{mg} / \mathrm{dL}$ ( $\geq 11.1 \mathrm{mmol} / \mathrm{L}$ ) accompanied by symptoms was observed, or when an oral glucose tolerance test showed a value $\geq 200 \mathrm{mg} / \mathrm{dL}$.

Loss of renal function was considered to be one endpoint in our study. For this purpose, we assessed the increase in serum creatinine during follow-up. Patients who had an increase of serum creatinine higher than $30 \%$ compared to baseline level (time of CAN diagnosis) at the end of follow-up were defined as non-responders. Conversely, all patients who did not lose graft function or those 
who showed a less than $30 \%$ increase in serum creatinine over time were defined as responders. Thus, the two patient groups were subdivided into responders (G1a, N = 71 , and $\mathrm{G} 2 \mathrm{a}, \mathrm{N}=51$ ) and non-responders (G1b, $N=10$, and $\mathrm{G} 2 \mathrm{~b}, \mathrm{~N}=29$ ).

\section{Histological analysis}

Biopsy specimens were evaluated and graded according to the Banff 97 criteria and the histological chronic allograft damage index (CADI) $(31,32)$. At least four slides were used to quantitate the histological changes in each biopsy stained with hematoxylin-eosin, Masson's trichrome, periodic acid-Schiff, and silver, respectively. All biopsy specimens were reviewed by three independent observers (pathologists) before inclusion of the patient in the study. The final result regarding the severity of acute and chronic lesions in each renal compartment was calculated by applying concordance criteria among these observers. In the case of discrepancy among the three pathologists, the mode of the values for each variable was used as the final grade of lesion severity.

\section{Statistical analyses}

Pre-transplant demographic characteristics used for covariate-adjusted analysis included the type of dialysis therapy (hemodialysis vs peritoneal dialysis) and the source of the graft (deceased vs living donor). The age of the donor (above or below 39 years) and the age of the recipient (above or below 34 years) were dichotomized. The cut-off was obtained based on the mean values. The post-transplant variables included the presence of proteinuria in 24-h collected samples, delayed graft function, early and late acute rejection, and cold ischemia time (above or below $60 \mathrm{~min}$ ). We examined the proportionalhazard assumption by plotting the graft survival curves for each group of a covariate on a log-log scale. Since the curves appeared to be reasonably parallel, we regarded the model as appropriate.

A CADI score of 2.3 or higher, a Banff 97 grade higher than II, a serum creatinine level of $2.5 \mathrm{mg} / \mathrm{dL}$ or higher, creatinine clearance of $60 \mathrm{~mL} / \mathrm{min}$, proteinuria of $1 \mathrm{~g} / 24 \mathrm{~h}$ or higher, were considered as cut-off points for statistical comparison among groups. The cut-off was obtained based on its best value to predict renal allograft loss. In order to assess the effect of ACEl therapy alone or in combination with MMF on erythropoiesis, we determined hematocrit levels immediately before the use of ACEI and at the end of follow-up.

The Kaplan-Meier method was used to estimate graft survival after CAN diagnosis. Graft loss was defined by the requirement of permanent dialysis after graft failure, and death of patients with functioning grafts was not considered as an end-point event. We determined statistical significance by log-rank comparisons of survival curves using two-sided $\mathrm{P}$ values. Values are reported as means \pm $\mathrm{SD}$ and, when appropriate, as median and ranges. Parametric and non-parametric tests, the chi-square test and Fisher's exact test were applied to compare demographic covariates between groups when appropriate. A P value of less than 0.05 was considered to be significant.

A multivariate Cox proportional hazards model was used to analyze the relation between graft loss and other covariates that were significant in univariate analysis or were well-known to be involved in graft loss. The Cox proportional hazard model-enter stepwise procedure was used to obtain the final model of significant predictors. Confounding variables were analyzed when required and were considered to be absent when the exponential coefficient (OR) did not change by more than $10 \%$. The Stata statistical software 12.0 was used for all statistical analyses (Stata Corporation, USA).

\section{Results}

\section{Demographic data of the study population}

The demographic characteristics of the population are reported in Tables 1 and 2 . The initial immunosuppression therapy was cyclosporine for 137 patients (85\%), tacrolimus for 18 (11\%), MMF for 32 (20\%), azathioprine for 115 (71\%), and sirolimus for $11(6 \%)$. Univariate analysis revealed that dialysis time $(P=0.014)$, recipient age $(P=$ 0.000 ), hepatitis ( $B$ or $C$ virus-positive serology; $P=0.014$ ), and post-transplant diabetes mellitus $(P=0.007)$ were significantly higher in G1. At the time of ACEI therapy initiation there were no differences in CAN grade between the groups or, interestingly, in serum creatinine levels (Table 2).

\section{ACEI and/or MMF therapy in patients with CAN}

Patients with CAN who used ACEI (G1) showed a marked reduction in proteinuria compared to the group that did not use ACEI (G2). Furthermore, their serum creatinine levels stabilized with time (Table 2).

The two groups (G1 and G2) were subdivided into responders and non-responders on the basis of an increase in baseline serum creatinine of more than $30 \%$ at the end of ACEI therapy. Responder patients on ACEI therapy not only showed stabilized renal function but also decreased proteinuria, whereas responder patients on ACEl-free therapy presented increased proteinuria. Some patients considered as non-responders in the ACEI therapy group showed increased serum creatinine during fol- 
low-up, although their proteinuria levels were reduced (Table 2).

The two groups were further subdivided on the basis of MMF use as described in Subjects and Methods. In general, patients with CAN who used ACEl combined or not with MMF showed decreased proteinuria. However, we only observed a statistically significant difference between patients who used ACEI and MMF after biopsy-proven CAN and the subgroup that did not use MMF or even those who were not treated with ACEI (Table 2). In contrast, among the patients who did not use ACEI, serum creati-

Table 1. Demographic data of the study population.

\begin{tabular}{|c|c|c|}
\hline Variables & $\begin{array}{l}\text { With ACEI } \\
(\mathrm{G} 1, \mathrm{~N}=81)\end{array}$ & $\begin{array}{l}\text { Without ACEI } \\
(G 2, N=80)\end{array}$ \\
\hline Recipient age (years) & $37 \pm 12$ & $30 \pm 12^{*}$ \\
\hline Donor age (years) & $35 \pm 13$ & $39 \pm 14$ \\
\hline Gender (male) & $54 \%$ & $46 \%$ \\
\hline Deceased donor & $38 \%$ & $37 \%$ \\
\hline \multicolumn{3}{|l|}{ HLA matching (living-related donor) } \\
\hline I (identical HLA, O mismatch) & 20 & $2^{*}$ \\
\hline II (50\% mismatch HLA) & 66 & 76 \\
\hline III (different HLA) & 14 & 22 \\
\hline Hemodialysis therapy & $95 \%$ & $75 \%$ \\
\hline Hemodialysis time (months) & $47 \pm 41$ & $33 \pm 30^{*}$ \\
\hline Cold ischemia time (min) & $698 \pm 1580$ & $564 \pm 747$ \\
\hline Early acute renal rejection & $40 \%$ & $44 \%$ \\
\hline Later acute renal rejection & $11 \%$ & $19 \%$ \\
\hline Delayed graft function & $31 \%$ & $38 \%$ \\
\hline Diabetes mellitus after transplantation & $18 \%$ & $5 \% *$ \\
\hline Anti-cytomegalovirus antibodies (IgG) & $18 \%$ & $16 \%$ \\
\hline Hepatitis (B or C virus) & $28 \%$ & $20 \% *$ \\
\hline \multicolumn{3}{|l|}{ CAN grade at first biopsy } \\
\hline CAN grade 1 & $50 \%$ & $63 \%$ \\
\hline CAN grade 2 & $39 \%$ & $27 \%$ \\
\hline CAN grade 3 & $11 \%$ & $10 \%$ \\
\hline CADI score $>2.3$ & $59 \%$ & $46 \%$ \\
\hline \multicolumn{3}{|l|}{ Initial immunosuppressive therapy, N (\%) } \\
\hline Cyclosporine & $75(54 \%)$ & $62(45 \%)^{*}$ \\
\hline Tacrolimus & $2(11 \%)$ & $16(89 \%)^{*}$ \\
\hline Rapamycin & $4(49 \%)$ & $7(51 \%)$ \\
\hline Azathioprine & $62(54 \%)$ & $53(46 \%)$ \\
\hline MMF & $14(44 \%)$ & $18(56 \%)$ \\
\hline \multicolumn{3}{|l|}{ Final immunosuppressive therapy, N (\%) } \\
\hline Cyclosporine & $65(52 \%)$ & $61(48 \%)$ \\
\hline Tacrolimus & $4(22 \%)$ & $19(78 \%)^{*}$ \\
\hline Rapamycin & $2(40 \%)$ & $3(60 \%)$ \\
\hline Azathioprine & $13(45 \%)$ & $16(55 \%)$ \\
\hline MMF & $55(56 \%)$ & $43(44 \%)^{*}$ \\
\hline
\end{tabular}

Data are reported as means \pm SD or percent. $\mathrm{ACEI}=$ angiotensin-converting enzyme inhibitor; HLA = human leukocyte antigen; $\mathrm{CAN}=$ chronic allograft nephropathy; $\mathrm{CADI}=$ chronic allograft damage index; $\mathrm{MMF}=$ mycophenolate mofetil. ${ }^{*} \mathrm{P}<0.05$ compared with ACEI (Student $t$-test for independent samples and chi-square test in categorical variables, both used in normal distribution of variables). nine and proteinuria were significantly increased only in the group who never used ACEI or MMF (serum creatinine: $2.0 \pm 0.8$ vs $2.4 \pm 1.6 \mathrm{mg} / \mathrm{dL} ; \mathrm{P}=0.001$, proteinuria: $0.4 \pm$ 0.5 vs $1.1 \pm 1.2 \mathrm{~g} / 24 \mathrm{~h}, \mathrm{P}<0.05$; Table 2 ).

In order to assess the effect of ACEl alone or in combination with MMF on erythropoiesis, we determined the hematocrit levels immediately before the use of ACEI and at the end of follow-up. In general, ACEl therapy was associated with a significant decrease in hematocrit levels. Patients on ACEl-free therapy, although presenting a reduction in hematocrit levels, only showed a statistically significant difference when also taking MMF. The association with MMF aggravated anemia (Table 3).

\section{Allograft survival and multivariate analyses}

Figure 1 shows the Kaplan-Meier estimate of graft survival for patients receiving ACEI therapy (G1) and ACEl-free therapy (G2). ACEI therapy was associated with better graft survival after CAN diagnosis. Multiple ACEI and MMF combinations were analyzed in a graft survival model. The use of MMF increased graft survival in patients who did not use ACEI. In this respect, the group that did not use ACEl or MMF had a median $65 \%$ censored population, the shortest survival time among the groups $(P=$ 0.02; Figure 1).

When we analyzed the survival model using other variables, such as acute rejection, co-morbidities, CAN grade, CADI score $\geq 2.3$, deceased donor, recipient and donor ages, cold ischemic time, hemodialysis therapy, delayed graft function, and antiCMV antibodies, we did not observe any correlations with graft survival rate. The use of ACEI or MMF therapy was positively associated with graft survival (Table 4) even when some of these variables were tested in multivariate analyses.

Cox regression analyses demonstrated that the use of ACEI therapy protected $79 \%$ of the patients against graft loss (OR = $0.079,95 \% \mathrm{Cl}=0.015-0.426 ; \mathrm{P}=0.003$ ), showing that ACEI therapy is a protective factor. The same trend was observed, but to a lesser extent, for those patients who did not use ACEI therapy but who were on MMF therapy after biopsy-proven CAN, and in 
Table 2. Renal function (serum creatinine, Scr, $\mathrm{mg} / \mathrm{dL}$ ) and proteinuria levels (Prot, g/24 h) at enrollment (Scr 1 and Prot 1 ) and at the end of follow-up (Scr 2 and Prot 2) in patients with or without ACEI therapy (responders = patients who did not lose graft function or those who showed less than a $30 \%$ increase in serum creatinine over time and non-responders), stratified or not for the use of MMF.

\begin{tabular}{|c|c|c|c|c|}
\hline Subgroups & Scr 1 & Scr 2 & Prot 1 & Prot 2 \\
\hline ACEI therapy (G1) & $1.81 \pm 0.56$ & $1.87 \pm 0.52$ & $1.31 \pm 1.94$ & $0.53 \pm 0.68^{*}$ \\
\hline No use of MMF $(\mathrm{N}=12)$ & $1.8 \pm 0.7$ & $1.8 \pm 0.6$ & $1.2 \pm 1.2$ & $0.6 \pm 0.7$ \\
\hline MMF pre $(\mathrm{N}=14)$ & $2.0 \pm 0.6$ & $2.0 \pm 0.5$ & $0.9 \pm 1.6$ & $0.3 \pm 0.4$ \\
\hline MMF post $(\mathrm{N}=55)$ & $1.8 \pm 0.5$ & $1.8 \pm 0.5$ & $1.4 \pm 2.0$ & $0.6 \pm 0.7^{\star}$ \\
\hline ACEl-free therapy (G2) & $2.07 \pm 0.73$ & $2.65 \pm 1.64^{*}$ & $0.51 \pm 0.74$ & $0.85 \pm 1.01^{*}$ \\
\hline No use of MMF $(\mathrm{N}=19)$ & $2.0 \pm 0.8^{*}$ & $2.4 \pm 1.6^{*}$ & $0.4 \pm 0.5^{*}$ & $1.1 \pm 1.2^{*}$ \\
\hline MMF pre $(\mathrm{N}=18)$ & $2.1 \pm 0.7$ & $2.9 \pm 2.1$ & $0.6 \pm 1.1$ & $0.8 \pm 1.1$ \\
\hline MMF post $(\mathrm{N}=43)$ & $2.0 \pm 0.7$ & $2.4 \pm 1.3$ & $0.5 \pm 0.7$ & $0.7 \pm 0.9$ \\
\hline \multicolumn{5}{|l|}{ ACEI treatment } \\
\hline Responders & $1.84 \pm 0.57$ & $1.83 \pm 0.51$ & $1.33 \pm 2.00$ & $0.52 \pm 0.68^{*}$ \\
\hline Non-responders & $1.52 \pm 0.32$ & $2.27 \pm 0.52^{\star}$ & $1.10 \pm 1.12$ & $0.71 \pm 0.70$ \\
\hline \multicolumn{5}{|l|}{ ACEI-free treatment } \\
\hline Responders & $1.94 \pm 0.54$ & $1.85 \pm 0.55$ & $0.38 \pm 0.41$ & $0.54 \pm 0.56^{*}$ \\
\hline Non-responders & $2.28 \pm 0.40$ & $4.05 \pm 1.96^{*}$ & $0.74 \pm 1.08$ & $1.40 \pm 1.37^{*}$ \\
\hline
\end{tabular}

Data are reported as mean $\pm \mathrm{SD}$. ACEI $=$ angiotensin converting enzyme inhibitor; MMF $=$ mycophenolate mofetil. ${ }^{*} P<0.05$, Scr $1 v s$ Scr2 and Prot1vs Prot2 (Student $t$-test).

Table 3. Hematocrit values immediately before the introduction of $\mathrm{ACEI}$ and at the end of follow-up in patients with or without ACEI therapy, stratified or not for the use of MMF.

\begin{tabular}{llc}
\hline Subgroups & Before & After \\
\hline ACEl therapy (G1) & & \\
$\quad$ No use of MMF $(\mathrm{N}=12)$ & $39 \pm 6.8$ & $34 \pm 7.4^{*}$ \\
MMF pre $(\mathrm{N}=14)$ & $42 \pm 6.9$ & $36 \pm 4.2^{*}$ \\
$\quad$ MMF post $(\mathrm{N}=55)$ & $41 \pm 7.4$ & $35 \pm 4.2^{*}$ \\
ACEl-free therapy $(\mathrm{G} 2)$ & & \\
$\quad$ No use of MMF $(\mathrm{N}=19)$ & $39 \pm 5.8$ & $36 \pm 6.1$ \\
MMF pre $(\mathrm{N}=18)$ & $40 \pm 6.4$ & $38 \pm 6.5$ \\
MMF post $(\mathrm{N}=43)$ & $39 \pm 7.0$ & $35 \pm 6.1^{*}$ \\
\hline
\end{tabular}

Data are reported as means \pm SD. ACEI = angiotensin-converting enzyme inhibitor; MMF $=$ mycophenolate mofetil. ${ }^{*} P<0.05$ compared to "before" (Student $t$-test for the same sample).

Figure 1. Graft survival curves for G1 (patient with $A C E I$ ) and $\mathrm{G} 2$ (patient without $\mathrm{ACEI}$ ) renal transplanted patients. $A$, Graft survival was analyzed after the diagnosis of chronic allograft nephropathy (CAN) in G1 and G2. B, Graft survival was also analyzed in both groups stratified for the use of mycophenolate mofetil (MMF) before (pre) or after (post) CAN diagnosis, and not. All survival curves showed significant differences.

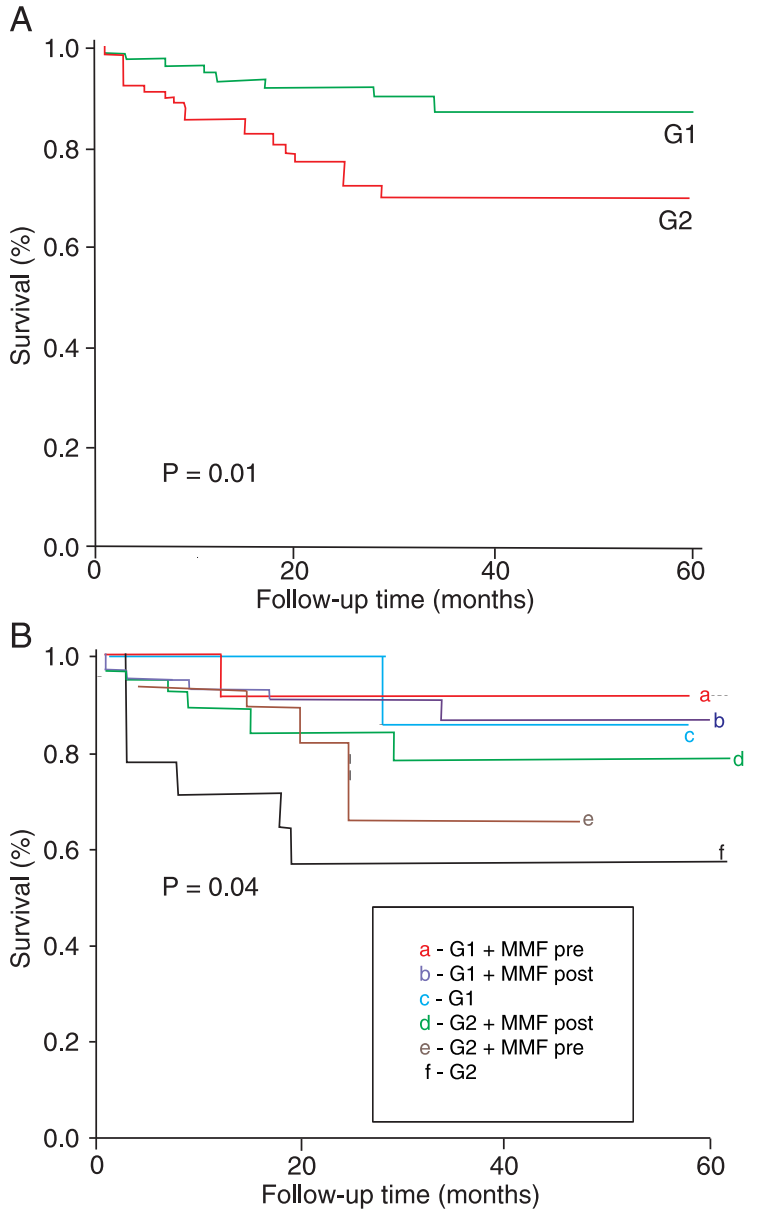


Table 4. Univariate analyses of patients with graft loss.

\begin{tabular}{lcc}
\hline Variables & $\begin{array}{c}\text { No graft loss } \\
(\mathrm{N}=132)\end{array}$ & $\begin{array}{c}\text { Graft loss } \\
(\mathrm{N}=29)\end{array}$ \\
\hline Recipient age (years) & $32 \pm 13$ & $34 \pm 12$ \\
Donor age (years) & $36 \pm 15$ & $37 \pm 14$ \\
Gender (male) & $85(82 \%)$ & $14(18 \%)$ \\
Deceased donor & $44(37 \%)$ & $12(41 \%)$ \\
Hemodialysis therapy & $123(93)$ & $29(100)$ \\
Cold ischemic time (min) & $660 \pm 823$ & $634 \pm 1309$ \\
Early acute renal rejection & $54(41 \%)$ & $13(45 \%)$ \\
Delayed graft function & $44(33 \%)$ & $11(38 \%)$ \\
Diabetes mellitus post-transplantation & $15(11 \%)$ & $4(14 \%)$ \\
Anti-cytomegalovirus antibodies (IgG) & $22(17 \%)$ & $6(21 \%)$ \\
ACEI use & $71(54 \%)$ & $10(35 \%)^{*}$ \\
Use of MMF after CAN diagnosis & $102(77 \%)$ & $17(58.6 \%)^{*}$ \\
\hline
\end{tabular}

Data are reported as means \pm SD or $\mathrm{N}(\%)$. ACEI = angiotensin-converting enzyme inhibitor; MMF = mycophenolate mofetil; $\mathrm{CAN}=$ chronic allograft nephropathy. ${ }^{*} \mathrm{P}<0.05$ compared to no graft loss (Student $t$-test for independent samples and chi-square test in categorical variables, both used in normal distribution of variables).

Table 5. COX-adjusted analysis model for graft loss in the population studied.

\begin{tabular}{lccc}
\hline Variables & P & OR & $95 \% \mathrm{Cl}$ \\
\hline Use of ACEI & 0.003 & 0.079 & $0.015-0.426$ \\
No use of ACEI, but use of MMF post-CAN & 0.024 & 0.108 & $0.016-0.743$ \\
Use of MMF post-CAN & 0.001 & 0.196 & $0.072-0.529$ \\
Donor age ( $\geq 39$ years) & 0.339 & 1.556 & $0.628-3.856$ \\
Acute rejection & 0.360 & 1.448 & $0.656-3.194$ \\
Delayed graft function & 0.451 & 1.415 & $0.574-3.488$ \\
Recipient age ( $\geq 34$ years) & 0.495 & 1.340 & $0.579-3.102$ \\
HLA matching (living-related donor) & 0.190 & 1.297 & $0.879-1.915$ \\
Gender (male) & 0.571 & 1.270 & $0.555-2.909$ \\
\hline
\end{tabular}

$\mathrm{ACEI}=$ angiotensin-converting enzyme inhibitor; $\mathrm{MMF}=$ mycophenolate mofetil; CAN = chronic allograft nephropathy.

those who were on ACEI therapy and who initiated MMF after biopsy-proven CAN (Table 5).

\section{Discussion}

The renoprotective effect of ACEI has been established in a wide variety of progressive diabetic and nondiabetic renal diseases (14-21). In renal transplantation, few clinical studies have shown the beneficial effects of ACEI therapy (19-21). Interestingly, a reduction in endstage renal disease was observed even in clinical cardiovascular studies evaluating the benefit of ACEI therapy in reducing mortality and cardiovascular effects (33).
Our results showed that ACEI therapy in patients with CAN could slow its progression, stabilizing serum creatinine and decreasing and limiting the progression of proteinuria as well as histological lesions. Patients who received ACEI maintained stable renal function with decreasing proteinuria at the end of therapy, in contrast to the ACEl-free group who presented a progressive loss of renal function with increasing proteinuria. These findings correlated with the results of other renal disease progression studies such as the Ramipril Efficacy in Nephropathy study of proteinuric nondiabetic nephropathies (16). ACEl therapy was associated with increased baseline glomerular filtration rate, possibly indicating a functional regression of renal disease in some patients.

However, recent data reported by Opelz et al. (34) demonstrated that no improvement in patient or graft survival outcome was found in kidney and heart transplant recipients on $\mathrm{ACEl} /$ angiotensin receptor blocker (ARB) treatment. Another retrospective study evaluated the patient and graft survival rates of 2031 recipients of a first kidney transplant with or without ACEI and/or ARB therapy. Heinze et al. (35) found a marked improvement in ten-year graft survival in patients on ACEI/ARB treatment. In these two recent retrospective studies, the authors did not specifically analyze the impact on patients with CAN diagnosed by biopsy, for whom the impact of ACEI/ARB therapy could be more pronounced.

In this context, an elegant experimental study from the group of Remuzzi (14) showed that ACEI therapy could stop proteinuria and glomerulosclerosis, interrupting the progression of chronic allograft dysfunction and injury.

After MMF was introduced in renal transplantation, some reports have demonstrated its benefit in CAN (22-24). Ojo et al. (22), in a study on 66,774 human renal allograft recipients, showed that MMF reduces late allograft loss independently of its effects on acute rejection. Experimental studies have long evaluated the impact of MMF in rodent models of end-stage renal disease. In experimental diabetes involving chronic nitric oxide synthase inhibition in rat models, the use of MMF prevented the development of glomerular atrophy and the progression of tubular atrophy and tubulointerstitial fibrosis $(36,37)$.

In the present study, MMF had a synergistic effect with ACEI since the combination of ACEI and MMF maintained serum creatinine stable throughout the study and decreased proteinuria more than when MMF was used alone. 
The combination of MMF and ACEI was a good prognostic factor for graft survival even in patients with established CAN. The death-censored graft survival analysis was much better for the group treated with ACEI alone, following the group treated with $\mathrm{ACEl}$ in combination with MMF, whereas the group receiving neither ACEI nor MMF showed the worst renal allograft outcomes.

The main limitation of our study was the influence of ACEI and MMF therapy on erythropoiesis. Both therapies were associated with a decrease in hematocrit levels. However, this side effect should not limit the use of ACEI in combination with MMF, with anemia being carefully monitored and the administration of an erythropoietin supplement being considered whenever necessary.

The present study was not randomized and has some of the limitations of retrospective studies. Many other con- founding factors could not be eliminated by the statistical approach used, and should be kept in mind. Randomized clinical trials would be ideal. However, they involve important ethical issues since experimental studies and metaanalyses of non-transplanted patients have demonstrated the benefit of both drugs.

Our results indicate that the use of ACEI alone or in combination with MMF significantly reduces proteinuria and stabilizes serum creatinine over time, consequently improving renal allograft survival.

\section{Acknowledgments}

The authors wish to thank Prof. Francisco Ortega and Carolina-BBVA Foundation, Spain, for unconditional help during the writing of this manuscript.

\section{References}

1. Di Paolo S, Schena A, Stallone G, Grandaliano G, Soccio $M$, Cerullo $G$, et al. Captopril enhances transforming growth factor (TGF)-beta1 expression in peripheral blood mononuclear cells: a mechanism independent from angiotensin converting enzyme inhibition? A study in cyclosporinetreated kidney-transplanted patients. Transplantation 2002; 74: 1710-1715.

2. Szabo A, Lutz J, Schleimer K, Antus B, Hamar P, Philipp T, et al. Effect of angiotensin-converting enzyme inhibition on growth factor mRNA in chronic renal allograft rejection in the rat. Kidney Int 2000; 57: 982-991.

3. Nankivell BJ, Borrows RJ, Fung CL, O'Connell PJ, Allen $\mathrm{RD}$, Chapman JR. The natural history of chronic allograft nephropathy. N Engl J Med 2003; 349: 2326-2333.

4. Joosten SA, Sijpkens YW, van Kooten C, Paul LC. Chronic renal allograft rejection: pathophysiologic considerations. Kidney Int 2005; 68: 1-13.

5. Massy ZA, Guijarro C, Wiederkehr MR, Ma JZ, Kasiske BL. Chronic renal allograft rejection: immunologic and nonimmunologic risk factors. Kidney Int 1996; 49: 518-524.

6. Tullius SG, Hancock WW, Heemann U, Azuma H, Tilney NL. Reversibility of chronic renal allograft rejection. Critical effect of time after transplantation suggests both host immune dependent and independent phases of progressive injury. Transplantation 1994; 58: 93-99.

7. Ma J, Matsusaka T, Yang H, Kawachi H, Shimizu F, Isaka $\mathrm{Y}$, et al. Local actions of endogenous angiotensin II in injured glomeruli. J Am Soc Nephrol 2004; 15: 1268-1276.

8. Anderson PW, Zhang XY, Tian J, Correale JD, Xi XP, Yang $\mathrm{D}$, et al. Insulin and angiotensin II are additive in stimulating TGF-beta 1 and matrix mRNAs in mesangial cells. Kidney Int 1996; 50: 745-753.

9. Remuzzi A, Gagliardini E, Donadoni C, Fassi A, Sangalli F, Lepre MS, et al. Effect of angiotensin II antagonism on the regression of kidney disease in the rat. Kidney Int 2002; 62: 885-894.

10. Ma LJ, Nakamura S, Whitsitt JS, Marcantoni C, Davidson
JM, Fogo AB. Regression of sclerosis in aging by an angiotensin inhibition-induced decrease in PAl-1. Kidney Int 2000; 58: 2425-2436.

11. Remuzzi A, Fassi A, Bertani T, Perico N, Remuzzi G. ACE inhibition induces regression of proteinuria and halts progression of renal damage in a genetic model of progressive nephropathy. Am J Kidney Dis 1999; 34: 626-632.

12. Adamczak M, Gross ML, Amann K, Ritz E. Reversal of glomerular lesions involves coordinated restructuring of glomerular microvasculature. J Am Soc Nephrol 2004; 15: 3063-3072.

13. Ma LJ, Nakamura S, Aldigier JC, Rossini M, Yang H, Liang $X$, et al. Regression of glomerulosclerosis with high-dose angiotensin inhibition is linked to decreased plasminogen activator inhibitor-1. J Am Soc Nephrol 2005; 16: 966-976.

14. Remuzzi G, Benigni A, Remuzzi A. Mechanisms of progression and regression of renal lesions of chronic nephropathies and diabetes. J Clin Invest 2006; 116: 288-296.

15. Taal MW, Brenner BM. Renoprotective benefits of RAS inhibition: from ACEI to angiotensin II antagonists. Kidney Int 2000; 57: 1803-1817.

16. Ruggenenti P, Perna A, Remuzzi G. ACE inhibitors to prevent end-stage renal disease: when to start and why possibly never to stop: a post hoc analysis of the REIN trial results. Ramipril Efficacy in Nephropathy. J Am Soc Nephrol 2001; 12: 2832-2837.

17. Kshirsagar AV, Joy MS, Hogan SL, Falk RJ, Colindres RE. Effect of ACE inhibitors in diabetic and nondiabetic chronic renal disease: a systematic overview of randomized placebo-controlled trials. Am J Kidney Dis 2000; 35: 695-707.

18. Noris M, Mister M, Pezzotta A, Azzollini N, Cassis P, Benigni $A$, et al. ACE inhibition limits chronic injury of kidney transplant even with treatment started when lesions are established. Kidney Int 2003; 64: 2253-2261.

19. Remuzzi G, Perico N. Routine renin-angiotensin system blockade in renal transplantation? Curr Opin Nephrol Hypertens 2002; 11: 1-10. 
20. Zaltzman JS, Nash M, Chiu R, Prasad R. The benefits of renin-angiotensin blockade in renal transplant recipients with biopsy-proven allograft nephropathy. Nephrol Dial Transplant 2004; 19: 940-944.

21. Artz MA, Hilbrands LB, Borm G, Assmann KJ, Wetzels JF. Blockade of the renin-angiotensin system increases graft survival in patients with chronic allograft nephropathy. Nephrol Dial Transplant 2004; 19: 2852-2857.

22. Ojo $A O$, Meier-Kriesche $H U$, Hanson JA, Leichtman $A B$, Cibrik D, Magee JC, et al. Mycophenolate mofetil reduces late renal allograft loss independent of acute rejection. Transplantation 2000; 69: 2405-2409.

23. Kimball JA, Pescovitz MD, Book BK, Norman DJ. Reduced human IgG anti-ATGAM antibody formation in renal transplant recipients receiving mycophenolate mofetil. Transplantation 1995; 60: 1379-1383.

24. Merville P, Berge F, Deminiere C, Morel D, Chong G, Durand $D$, et al. Lower incidence of chronic allograft nephropathy at 1 year post-transplantation in patients treated with mycophenolate mofetil. Am J Transplant 2004; 4: 1769-1775.

25. Srinivas TR, Kaplan B, Schold JD, Meier-Kriesche HU. The impact of mycophenolate mofetil on long-term outcomes in kidney transplantation. Transplantation 2005; 80: S211S220.

26. Weir MR, Fink JC, Hanes DS, Gardner J, Klassen DK, Cangro $\mathrm{C}$, et al. Chronic allograft nephropathy: effect of cyclosporine reduction and addition of mycophenolate mofetil on progression of renal disease. Transplant Proc 1999; 31: 1286-1287.

27. Gonzalez Molina M, Seron D, Garcia del Moral R, Carrera M, Sola E, Jesus Alferez M, et al. Mycophenolate mofetil reduces deterioration of renal function in patients with chronic allograft nephropathy. A follow-up study by the Spanish Cooperative Study Group of Chronic Allograft Nephropathy. Transplantation 2004; 77: 215-220.

28. Yang CW, Ahn HJ, Kim WY, Li C, Jung JY, Yoon SA, et al. Synergistic effects of mycophenolate mofetil and losartan in a model of chronic cyclosporine nephropathy. Transplantation 2003; 75: 309-315.

29. Noris M, Azzollini N, Pezzotta A, Mister M, Benigni A, Marchetti G, et al. Combined treatment with mycophenolate mofetil and an angiotensin II receptor antagonist fully protects from chronic rejection in a rat model of renal allograft. $J$ Am Soc Nephrol 2001; 12: 1937-1946.

30. Rodriguez-Iturbe B, Pons H, Quiroz Y, Gordon K, Rincon J, Chavez M, et al. Mycophenolate mofetil prevents salt-sensitive hypertension resulting from angiotensin II exposure. Kidney Int 2001; 59: 2222-2232.

31. Racusen LC, Solez K, Colvin RB, Bonsib SM, Castro MC, Cavallo T, et al. The Banff 97 working classification of renal allograft pathology. Kidney Int 1999; 55: 713-723.

32. Isoniemi H, Taskinen E, Hayry P. Histological chronic allograft damage index accurately predicts chronic renal allograft rejection. Transplantation 1994; 58: 1195-1198.

33. Remuzzi G, Ruggenenti $P$. Overview of randomised trials of ACE inhibitors. Lancet 2006; 368: 555-556.

34. Opelz G, Zeier M, Laux G, Morath C, Dohler B. No improvement of patient or graft survival in transplant recipients treated with angiotensin-converting enzyme inhibitors or angiotensin II type 1 receptor blockers: a collaborative transplant study report. J Am Soc Nephrol 2006; 17: 3257-3262.

35. Heinze G, Mitterbauer C, Regele H, Kramar R, Winkelmayer WC, Curhan GC, et al. Angiotensin-converting enzyme inhibitor or angiotensin II type 1 receptor antagonist therapy is associated with prolonged patient and graft survival after renal transplantation. J Am Soc Nephrol 2006; 17: 889-899.

36. Utimura R, Fujihara CK, Mattar AL, Malheiros DM, Noronha IL, Zatz R. Mycophenolate mofetil prevents the development of glomerular injury in experimental diabetes. Kidney Int 2003; 63: 209-216.

37. Fujihara CK, Avancini Costa Malheiros DM, De Nucci G, Zatz R. Mycophenolate mofetil reduces renal injury in the chronic nitric oxide synthase inhibition model. Hypertension 2001; 37: 170-175. 